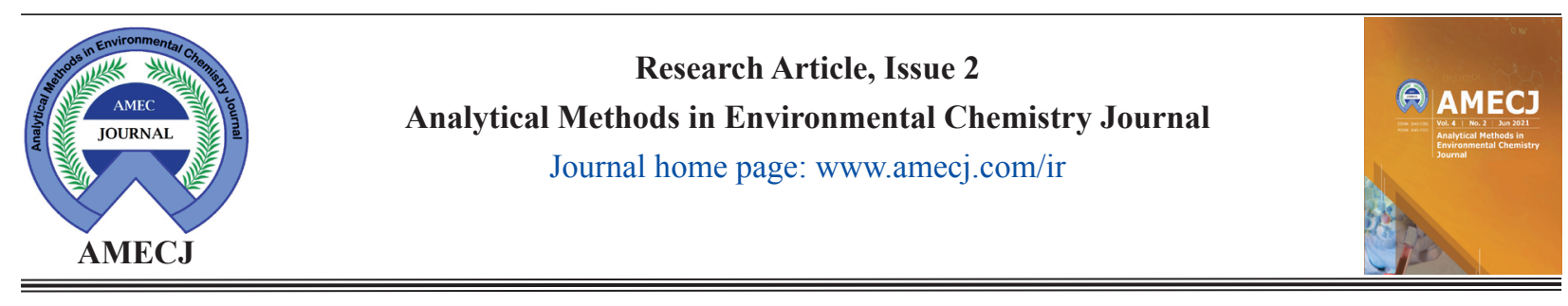

\title{
Development of electrodeposited nanostructural poly (o-aminophenol) coating as a solid phase microextraction fiber for determination of bisphenol A
}

\author{
Mohammad Saraji ${ }^{\mathrm{a}}$, Bahman Farajmand ${ }^{*, \mathrm{~b}}$ and Esmaeil Heydari Bafrouei \\ ${ }^{a}$ Department of Chemistry, Isfahan University of Technology, Isfahan, Iran. \\ ${ }^{b}$ Department of Chemistry, Faculty of Science, University of Zanjan, Zanjan, Iran. \\ ${ }^{C}$ Department of Chemistry, Vali-Asr University of Rafsanjan, Rafsanjan, Iran.
}

\section{A R T I C L E I N F O :}

Received 10 Mar 2021

Revised form 28 Apr 2021

Accepted 25 May 2021

Available online 28 Jun 2021

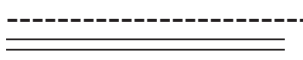

Keywords:

Poly (o-aminophenol),

Nanostructure,

Bisphenol A,

Solid phase microextraction,

Gas chromatography-flame ionization detector

\begin{abstract}
A B S T R A C T
In this research nanostructural poly (o-aminophenol) was synthesized by electropolymerization and used for solid phase microextraction fiber procedure (SPME). Thin film of Poly (o-aminophenol) $(4 \mu \mathrm{m}$ thickness) was shaped by sweep potential for $45 \mathrm{~min}$ on the surface of stainless steel wire. Polymer was synthesized by potentiostat procedure too. Prepared polymer by sweep potential procedure showed nanostructures on the surface. Acetic anhydride was employed for derivatization of bisphenol A (BPh-A) and analysis of acetylated $\mathrm{BPh}-\mathrm{A}$ was utilized by gas chromatography-flame ionization detector (GC-FID). Affecting parameters on derivatization and extraction such as amount of acetic anhydride, stirring rate, temperature, ionic strength and extraction time were optimized. The limit of detection (LOD) and relative standard divisions (RSDs\%) were achieved 0.6 $\mu \mathrm{gL}^{-1}$ and less than $6.8 \%$, respectively under optimized conditions. Finally proposed method was used for extraction of bisphenol A from leaching of baby and drinking water bottles. Relative recovery was achieved $98 \%$ for leaching from drinking bottle. In leaching from plastic baby bottle, bisphenol A (BPh-A) was detected in the range 5-15 $\mu \mathrm{g} \mathrm{L} \mathrm{L}^{-1}$.
\end{abstract}

\section{Introduction}

Solid phase microextraction (SPME) is a simple, solvent free and green sample preparation technique which includes the employing of a small amount of polymeric sorbent coated on a thin fiber for extraction [1]. Nowadays, commercial SPME fibers are available. The important disadvantages of commercial SPME fibers are high cost, frangibility of the fibers and weakness of sorbents for extraction of polar compounds. For domination of these drawbacks,

*Corresponding Author: Bahman Farajmand

Email: farajmand@znu.ac.ir

https://doi.org/10.24200/amecj.v4.i02.142 conductive polymers (CPs) such as polyaniline (PANI) and polypyrole (PPy), coated on the surface of metallic fiber, are good choices [2] but thermal instability of these CPs is a problem when gas chromatography is applied for followed analysis. Many solutions such as changing of counter ion [3] or doping carbon nanotube [4] and nanosilica [5] in the matrix of polymer, have been suggested for modifying of thermal stability and other properties of PANI and PPy. Application of other new CPs with multi-functional groups can be an alternative way for modifying of thermal stability, selectivity and extraction efficiency of SPME fibers. 
Poly (o-aminophenol) (POAP) has been an interesting polymer during three past decades. Many of researches have been performed about its synthesis, structure and application in sensor, biosensor and corrosion protection [6]. The POAP is formed by electrochemical oxidation of o-aminophenol (o-AP) on the surface of different electrode in aqueous solution. o-AP can be polymerized electrochemically in alkaline, neutral and acidic media. However, while a conducting polymer film is only produced in acidic media, POAP prepared in neutral and alkaline media leads to a nonconducting polymer film so, the polymer thickness of POAP synthesized in basic and natural media is limited within $10-100 \mathrm{~nm}$ due to a self-limiting growth [7]. The o-AP is containing $-\mathrm{OH}$ and $-\mathrm{NH}_{2}$ groups in ortho position on a phenyl ring. Polymerization of the o-AP can be performed by both groups therefore a ladder structure could be formed which has better thermal stability rather than PANI [8]. POAP has been employed to build biosensors, because it has been showed permselective properties so the interference from different electroactive species can be significantly reduced during the analysis of biological samples by utilizing a biosensor based on POAP. Moreover, as both hydroxyl and amino groups are involved in the electropolymerization process of o-aminophenol, large amounts of biological macromolecules such as glucose oxidase $[9,10]$ or horseradish peroxidase [11] could be immobilized in poly(oaminophenol), which results in higher sensitivity of the sensor as compared with sensors based on other polymers. on the other hands the presence of POAP as a sensing material can decrease the oxidation overpotential of some molecules, so it has shown the electrocatalytic behavior [12]. A hybrid modified electrode was also prepared by electropolymerization of $\mathrm{o}-\mathrm{AP}$ in the presence of sulfonated nickel phtalocyanine. The modified electrode could electrocatalyze NO oxidation and has been employed as NO sensor [13]. The copolymer poly(aniline-co-o-aminophenol) has been exhibited favorable properties to its application in sensors, electrocatalysis, analytic determinations and rechargeable batteries $[14,15]$. The $\mathrm{pH}$ dependence of the electroactivity of the copolymer is much better than that of PANI. Poly(aniline-co-oaminophenol) has been employed as sensor of catechol [16] and ascorbic acid [17]. POAP has been applied as a molecular imprinting polymer for sensor preparation. In this regard, an electrochemical sensor for nicotine based on the electropolymerization of o-PA as monomer and nicotine as template was proposed by Zhaoyang et al. [18]. Compared with nicotine imprinting membranes, the POAP film, was homogeneous, had nanometric thickness and its synthesis was easy. Other application of POAP film was reviewed by Tucerri [6].

Bisphenol A, (BPh-A), 2,2-bis(4-hydroxyphenyl) propane, is one of the highest volume chemicals in the world. It was applied for production of polycarbonate with the second largest outlet being epoxy resins [19]. A broad variety of food contact materials stand out among their uses, mainly derived from polycarbonates (infant feeding bottles, storage containers, tableware, returnable water, milk bottles and water pipes) and epoxy resins (internal protective lining for food and beverage cans, coating on metal lids for glass jars and bottles and drinking water storage tanks) [19]. The BPh-A has shown estrogenic activity so it acts as an endocrine disruptor. Furthermore, researches also has been indicated the potential of BPh-A to disrupt thyroid hormone action [20], to cause proliferation of human prostate cancer cells [21] and to block testosterone synthesis [22] at very low part-per-trillion doses So, there are needs for introducing of new analytical procedures particularly application of modern sample preparation methods (such as microextraction techniques) in order to have reliable tools for control of human exposure to BPh-A. SPME with commercial fibers was utilized for extraction of $\mathrm{BPh}-\mathrm{A}$ frequently [23-27]. Molecularly imprinted polymeric fiber was employed for selective extraction of $\mathrm{BPh}-\mathrm{A}$ from complex matrix which was shown by Tan et al. [28]. 
The POAP, as a multi-functional group compound, can be a remarkable sorbent for extraction of different analytes so, in this paper, nanostructural POAP coated on the stainless steel wire has been prepared by electropolymerization under cyclic voltametry and finally the polymeric coating was used as a SPME fiber for extraction of BPh-A from aqueous matrix. Different effective parameters on derivatization and extraction of BPh-A have been evaluated and optimized and finally the method has been applied for determination of BPh-A in leaching from drinking and plastic baby bottle that are made from polycarbonate.

\section{Experimental}

\subsection{Materials}

Bisphenol A was obtained from Sigma \& Aldrich (St. Louis, USA) and dissolved in methanol to make stock solution at the concentration of $500 \mathrm{mg} \mathrm{L}^{-1}$. Intermediate standard solution was prepared at concentration $10 \mathrm{mg} \mathrm{L}^{-1}$. More diluted working solutions used in optimization studies were prepared daily by diluting different amounts of the intermediate standard solution with pure water. All solutions were stored at $4{ }^{\circ} \mathrm{C}$ prior to use. HPLC grade methanol was purchased from Merck (Darmstadt, Germany). Sodium dodecyl sulfate (SDS), sulfuric acid, sodium chloride, sodium sulfate and o-aminophenol were purchased from Merck (Darmstadt, Germany). Sodium carbonate and acetic anhydride for derivatization of BPH-A was obtained from Merck too. Pure water was prepared by OES (Overseas Equipment \& Services) water purification system (OK, USA). The surgical grade stainless steel plunger of a disposable spinal needle $(27 \mathrm{G}$, Bartar Co., Tehran, Iran) was used as the substrate of the SPME fibers.

\subsection{Instrumentation}

The SPME device was purchased from Supelco (Bellefonte, PA, USA) and used for SPME experiments with commercial fibers $(85 \mu \mathrm{m}$ PA and $65 \mu \mathrm{m}$ PDMS/DVB). A homemade SPME holder was assembled and used to perform extraction with the fibers produced in the present work. A piece of stainless steel wire $(3 \mathrm{~cm})$ was mounted into the SPME device and used as a working electrode to make the SPME fiber. Electrochemical polymerization was carried out with a potentiastat/galvanostat AutoLab (Echo Chemie, Netherlands). A SP3420A gas chromatograph equipped with a split/ splitless injector and a flame ionization detector (BFRL, Beijing, China) was employed for all experiments. The injector was equipped with a low-volume insert designed for the analysis by SPME (Restek, Bellefonte, PA, USA). Nitrogen (99.999\%) was used as carrier and make-up gas. The carrier and make-up gas flow rate was set at 1.7 and $30 \mathrm{~mL} \mathrm{~min}^{-1}$, respectively. The chromatographic separation was performed using a DB-35ms, $10 \mathrm{~m} \times 0.25 \mathrm{~mm}$, fused silica capillary column with a $0.15 \mu \mathrm{m}$ stationary phase thickness (Supelco, Bellefonte, PA, USA). The injector and detector temperatures were set at 260 and $280{ }^{\circ} \mathrm{C}$, respectively. The column temperature was initially maintained at $100{ }^{\circ} \mathrm{C}$ for $1 \mathrm{~min}$; subsequently, the temperature was increased to $250{ }^{\circ} \mathrm{C}$ (at a rate of $30{ }^{\circ} \mathrm{C} \mathrm{min}{ }^{-1}$ ) and held for 10 min. Surface characteristic studies of the poly (o-aminophenol) coating was performed using field emission-scanning electron microscopy (FE-SEM) (Hitachi, S-4160, Japan). Chemical bonding characterization of the coating was investigated using Fourier transform infrared spectroscopy (FT-IR-350, Jasco Co., Tokyo, Japan). Thermogravimetric analysis (TGA) was performed using a Rheometric Scientific TGA 1500 instrument.

\subsection{Preparation of SPME coating}

Poly(o-aminophenol) film was prepared according to work of Kunimura et al [29] with some modification. Polymerization was performed with a potential-sweep electrolysis by using a standard three-electrode cell. Stainless steel wire (o.d. $0.2 \mathrm{~mm}$ ) and platinum electrode were used as working and counter electrodes. A length of 1 $\mathrm{cm}$ from the end part of stainless steel wire was 
immersed into the polymerization solution. The electrode potential was cycled between 0 and 1.3 $\mathrm{V}$ versus an $\mathrm{Ag} / \mathrm{AgCl}$ electrode at $50 \mathrm{mV} \mathrm{s}^{-1}$ in a $0.5 \mathrm{M} \mathrm{Na}_{2} \mathrm{~S}_{4}$ solution ( $\mathrm{pH}$ 1.0) containing 100 $\mathrm{mM}$ o-aminophenol and $0.05 \mathrm{mM}$ SDS (as the counter ion and catalyst). Solution was stirred magnetically by a $1 \mathrm{~cm}$ stir bar at $800 \mathrm{rpm}$. For the comparison purpose, polymer was synthesis at a constant potential of $1.3 \mathrm{~V}$ for $45 \mathrm{~min}$ too. To make the coating adhere firmly to the surface of the wire, the wire surface was first roughened by a smooth sand paper and then washed in methanol while sonicating. After polymerization, prepared fiber was thoroughly rinsed with distillated water and thermally conditioned before use. Thermal conditioning of the fibers was carried out by heating at $150{ }^{\circ} \mathrm{C}$ for $20 \mathrm{~min}$, then at $200{ }^{\circ} \mathrm{C}$ for 20 min, and finally at $290{ }^{\circ} \mathrm{C}$ for $20 \mathrm{~h}$ in a GC injector port under a nitrogen atmosphere.

\subsection{Derivatization and SPME procedure}

A $3.0 \mathrm{~mL}$ standard solution of BPH-A containing $0.05 \mathrm{~mol} \mathrm{~L}^{-1}$ of sodium carbonate was transferred into a $7-\mathrm{mL}$ glass vial from Supelco $(14 \mathrm{~mm}$ i.d.). A $13 \mathrm{~mm} \times 3 \mathrm{~mm}$ Teflon coated stir bar was used in the vial for stirring the solution. For derivatization step, amount of $25 \mu \mathrm{L}$ acetic anhydride was added to the vial. The vial was caped and reaction was performed for $5 \mathrm{~min}$ at 300 rpm and room temperature. After the reaction, 0.6 $\mathrm{g}$ of sodium chloride was added to the solution and magnetically stirred until dissolving. For extraction step, the SPME fiber was immersed into the sample solution under optimum stirring rate $(600 \mathrm{rpm})$ at room temperature. After 30 $\mathrm{min}$, the fiber was retracted into the needle and immediately introduced into the GC injection port $\left(260{ }^{\circ} \mathrm{C}\right)$. Injection was made in splitless mode and desorption time obtained at $3 \mathrm{~min}$.

\section{Results and discussion}

\subsection{Characterization of POAP coating}

The morphological structures of POAP coating were investigated with FE-SEM and have been shown in Figure 1. POAP coating prepared by sweep potential showed granular structures which were contained the large number of nanoparticles (o.d. $50 \mathrm{~nm}$ or smaller) attached to each other (Fig. 1a and b). However, in some places, nanoparticles were placed beside each other without any granular structure (Fig. 1d). The thickness of the coating was obtained about $4 \mu \mathrm{m}$ (Fig. 1c). It seems low conductivity of polymer causes the thickness does not increase in the period of electropolymerization [29]. Figure 1e and $f$ demonstrate surface morphology of POAP prepared by constant potential. As can be seen, polymer film is uniform and flat and there is no granular structure. Application of the fiber prepared by constant potential shows 4 times weaker result than the one prepared by sweep potential. It seems the higher surface area of the polymer film prepared by sweep potential plays important role in extraction of analyte.

For gas chromatography applications, SPME fibers must be have efficient thermal stability. The TGA curve of the POAP coating under argon atmosphere at a heating rate of $10{ }^{\circ} \mathrm{C} \mathrm{min}^{-1}$ has been shown in Figure 2a. This film was found to start a slow loss of weight around $300{ }^{\circ} \mathrm{C}$. The weight loss was at most $4 \%$ at this temperature which could be attributed to the evaporation of water moisture trapped in the pores of the film. So the present SPME fiber coating is stable at temperatures below $300{ }^{\circ} \mathrm{C}$ due to ladder chemical structure [29]. Then the fiber is suitable for gas chromatographic analysis.

Investigation of infrared spectroscopy of POAP was carried out by many researchers and more chemical structures have been proposed. o-AP has two functional groups which contains $-\mathrm{OH}$ and $-\mathrm{NH}_{2}$ sites. Polymerization of o-AP can be performed by both sites. Due to spectroscopic measurements, different structures have been proposed for POAP. Besides a completely ringclosed or ladder structure with phenoxazine units [8,30-32], other two structures, a partially ring opened and another partially hydrolyzed, have been considered for POAP. In-situ Raman spectroscopy measurements propose 


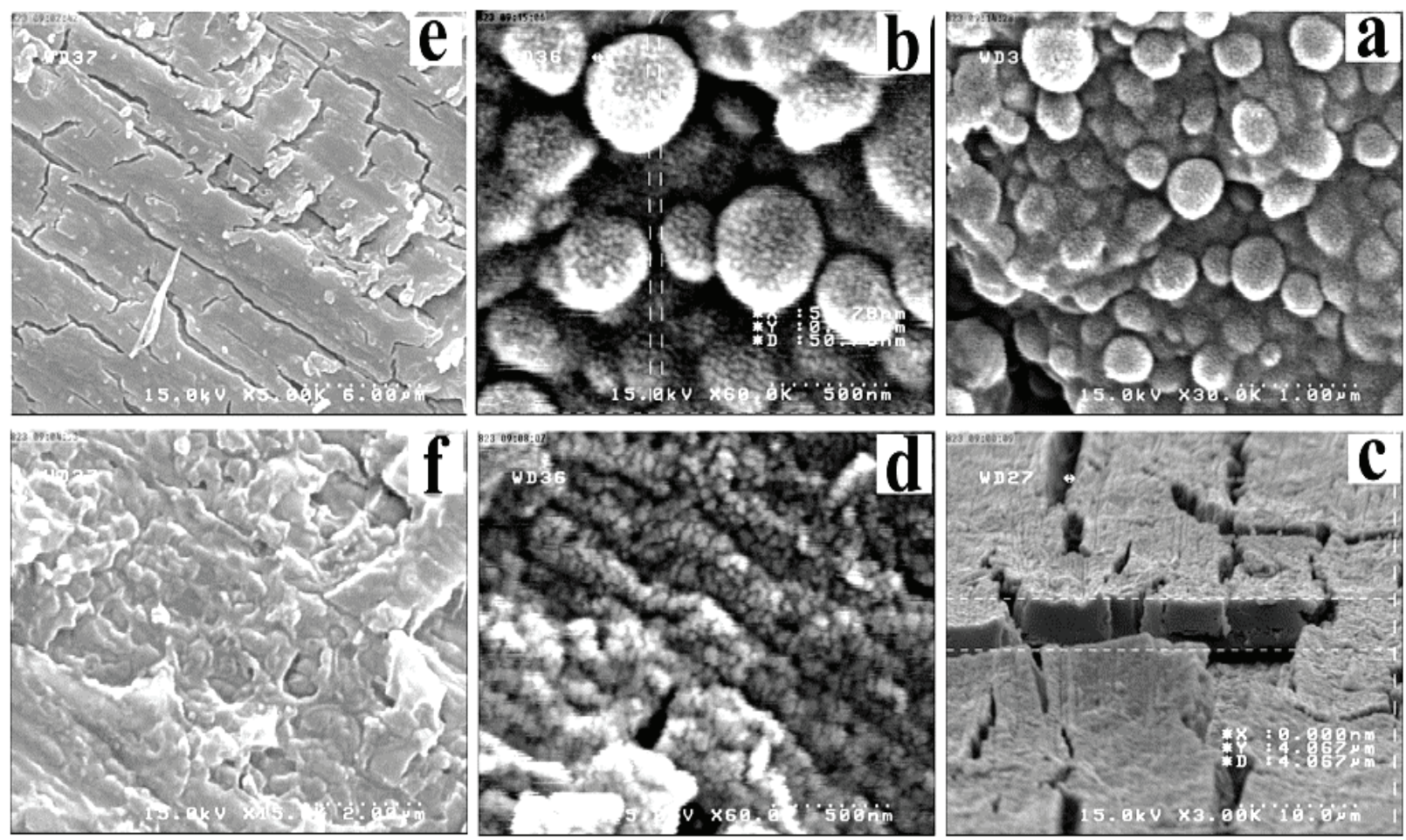

Fig. 1. FE-SEM images from POAP coated on the surface of stainless steel wire at (a, b, c \& d) cyclic potential between 0 and $1.3 \mathrm{~V}$ with $50 \mathrm{mV} / \mathrm{s}$ rate; (e \& f) constant potential at $1.3 \mathrm{~V}$.

that the POAP medium contains alternating oxidized (quinonoid) and reduced (N-phenylp-phenylenediamine) repeating units [33,34]. Zhang et al. introduced 1,4-substituted molecular structure for POAP $[33,34]$ allows explaining the interaction of the polymer with metal ions. The cation capturing process by POAP was certified to simultaneous presence of $-\mathrm{OH}$ and $-\mathrm{NH}_{2}$ groups of the polymeric backbone, in which the lone-pair electrons are available to form metal complex. IR studies have been indicated that the POAP film-growing process in alkaline media involves the deprotonation of the aminophenol molecule, which is probably chemisorbed at the metal surface, followed by oxidation and electropolymerization reactions. In this whole process, the polymerization affects the $-\mathrm{OH}$ group by the formation of $\mathrm{C}-\mathrm{O}-\mathrm{C}$ bond while the $-\mathrm{NH}_{2}$ groups are preserved [35].

In this study Fourier transform infrared spectroscopy (FT-IR) was used to investigate the functional groups of the polymer. Spectrum has been revealed in Figure 2b. Broad peak between 3000 and $4000 \mathrm{~cm}^{-1}$ assigned to the symmetric stretching of $\mathrm{NH}$ and $\mathrm{OH}$ in aromatic system. Strong peaks at 1582 and $1379 \mathrm{~cm}^{-1}$ are belonging to $\mathrm{C}-\mathrm{N}$ stretching vibrations for quinoide structure or combination band for protonated aromatic amine [36]. Strong peak at $1460 \mathrm{~cm}^{-1}$ can be assigned for $\mathrm{NH}$ scissoring vibrations. Weak peak at $1037 \mathrm{~cm}^{-1}$ is belonging to C-C stretching vibrations in benzene ring [36]. Consequently, a blend of structures could be considered for POAP film. A weak peak at $2926 \mathrm{~cm}^{-1}$ assigned to stretching of $\mathrm{CH}$ in aliphatic system which can be considered for dodecyl sulfate counter ion. SDS plays two roles for preparation of POAP. At first it acts as a catalyst and oxidation potential of o-AP was shifted to less positive potentials (almost $0.075 \mathrm{~V}$ ) and the oxidation current increased, as compared with the process in the absence of SDS. The rate of polymerization also increased considerably in the presence of SDS [37] on the other hands dodecyl sulfate has been used as a frequent counter ion in conductive polymer preparation that used for microextraction process because it increases thermal stability of polymeric film [38]. 


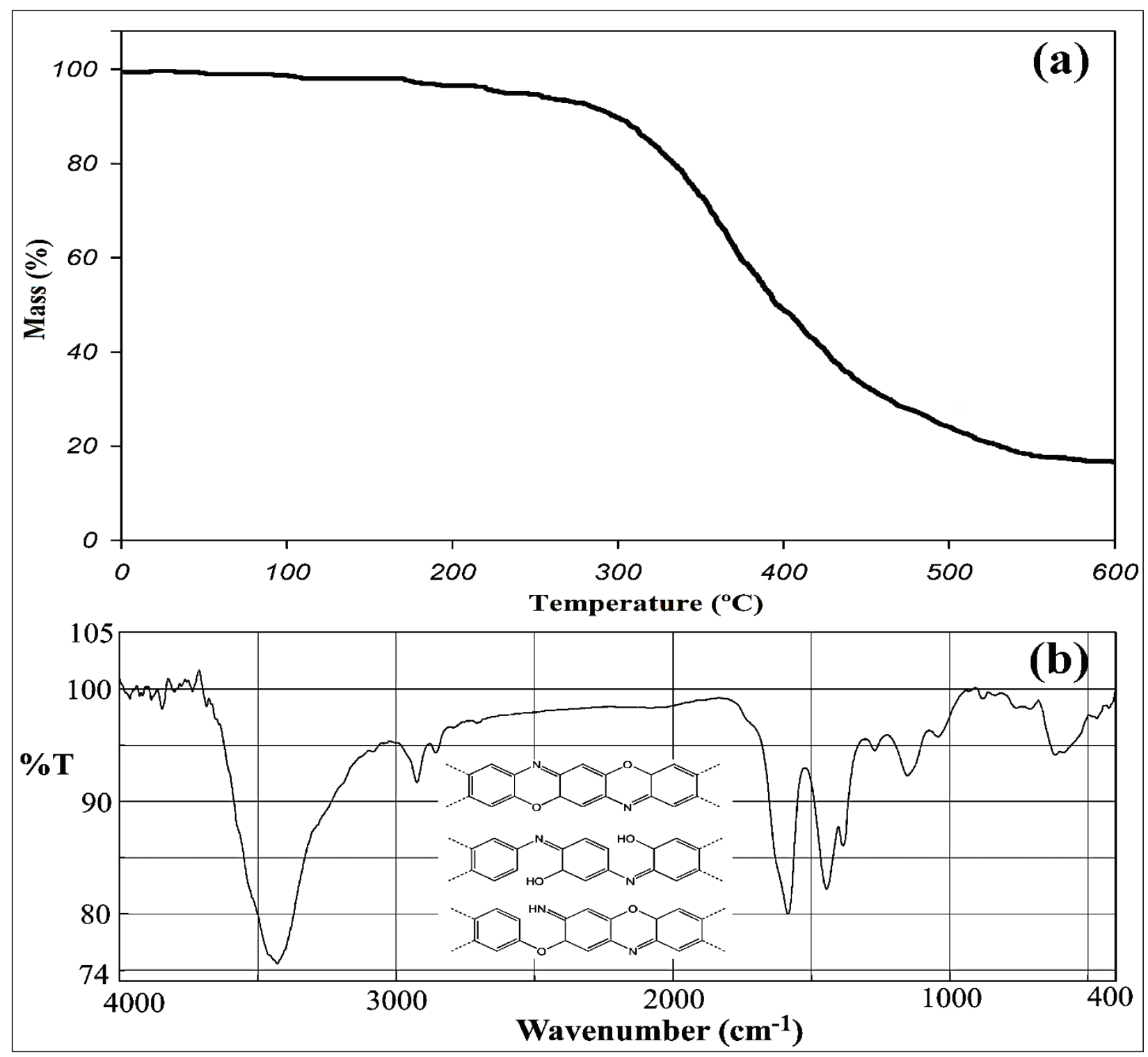

Fig. 2. Thermal gravimetric analysis (a) and FT-IR spectra of POAP coating prepared by sweep potential.

\subsection{Optimization of conditions}

For evaluation of POAP film as a solid phase microextraction fiber, effects of various parameters that can probably influence the performance of the derivatization and extraction of BPH-A, including amounts of acetic anhydride and sodium carbonat, salt concentration, stirring rate, extraction time and temperature were investigated. All experiments were performed three times.

\subsubsection{Optimization of derivatization conditions}

Derivatization canreducethepolarityofsomeanalytes and can improve the extraction efficiency and also it leads to better peak shape, and higher sensitivity. Acetic anhydride is a common derivatization reagent that has been applied for blocking of hydroxyl group of phenolic compounds frequently $[23,39,40]$. The derivatization with acetic anhydride was performed in situ. Consequently, the experimental variables affecting to both the extraction and derivatization processes were studied together. Derivatization of bisphenol A with acetic anhydride performs in basic condition. Sodium carbonate usually has been used for adjustment of sample $\mathrm{pH}$ hence in this research effect of different concentration of sodium carbonate was investigated. Figure $3 \mathrm{a}$ show the consequences. The concentrations of 0.05 and 0.1 
mol L-1 reveal maximum derivatization efficiency, Therefore, $0.05 \mathrm{~mol} \mathrm{~L}^{-1}$ of sodium carbonate was applied for adjustment of $\mathrm{pH}$. Under optimized $\mathrm{pH}$, the amount of acetic anhydride was evaluated for the best derivatization efficiency. Effect of different amount of acetic anhydride on extraction efficiency was summarized in Figure $3 \mathrm{~b}$. As can be seen, concentration more than $0.75 \%(\mathrm{~V} / \mathrm{V})$ has not significant effect on derivatization efficiency therefore this concentration was selected as an optimum point. Acetylation of phenolic compounds usually is completed at a short time nonetheless in this research the reaction time was studied too. The results satisfy that the times more than 5 min have not considerable effect on the reaction recovery (the curve has not shown).

\subsubsection{Optimization of extraction conditions}

Effective parameters such as ion strength, stirring rate, extraction temperature and time were evaluated and optimized. The ion strength of the sample solution was studied by spiking a series of $\mathrm{NaCl}$ concentrations of $0-0.3 \mathrm{~g} \mathrm{~L}^{-1}$. The response increases with the increase of ion strength; however, the extraction efficiency slightly decreases under the high salt content (Fig. 4a). A salt level of $0.2 \mathrm{~g} \mathrm{~mL}^{-1}$ of $\mathrm{NaCl}$ was used in the following experiments. The fiber is directly immersed in the liquid samples, and partitions between the sample matrix and the stationary phase were happened. Agitation of the sample is often carried out with a small stirring bar to decrease the time necessary for equilibrium and to decrease the tension of the static aqueous film. The stirring bar is of dimension $10 \mathrm{~mm} \times 3 \mathrm{~mm}$. The effect of the stirring rate on the responses was tested from 250 to $1000 \mathrm{rpm}$. At a higher stirring rate of $600 \mathrm{rpm}$, a significant decrease in the area response was observed (Fig. $4 \mathrm{~b})$. Moreover, better result was obtained at a relatively medium stirring rate than at the lower and higher ones. Thus, a stirring rate of $600 \mathrm{rpm}$ was chosen for further experiments. Temperature has kinetic and thermodynamic effects on extraction recovery. On the other hands, solubility of analyte in water increases at high temperature, so, effect of temperature in the range of 10 to 45 ${ }^{\circ} \mathrm{C}$ (Fig. 5a). Best results were achieved at $15{ }^{\circ} \mathrm{C}$ but for simplicity room temperature was applied as an optimal temperature. The extraction time was studied from $10 \mathrm{~min}$ to $60 \mathrm{~min}$ (Fig. 5b). The result shows that the equilibrium time is reached until 40 min when a further increase of the extraction time does not result in a significant increase in the detector response but for shortening the analysis time, an extraction time of $30 \mathrm{~min}$ was established in all the experiments.
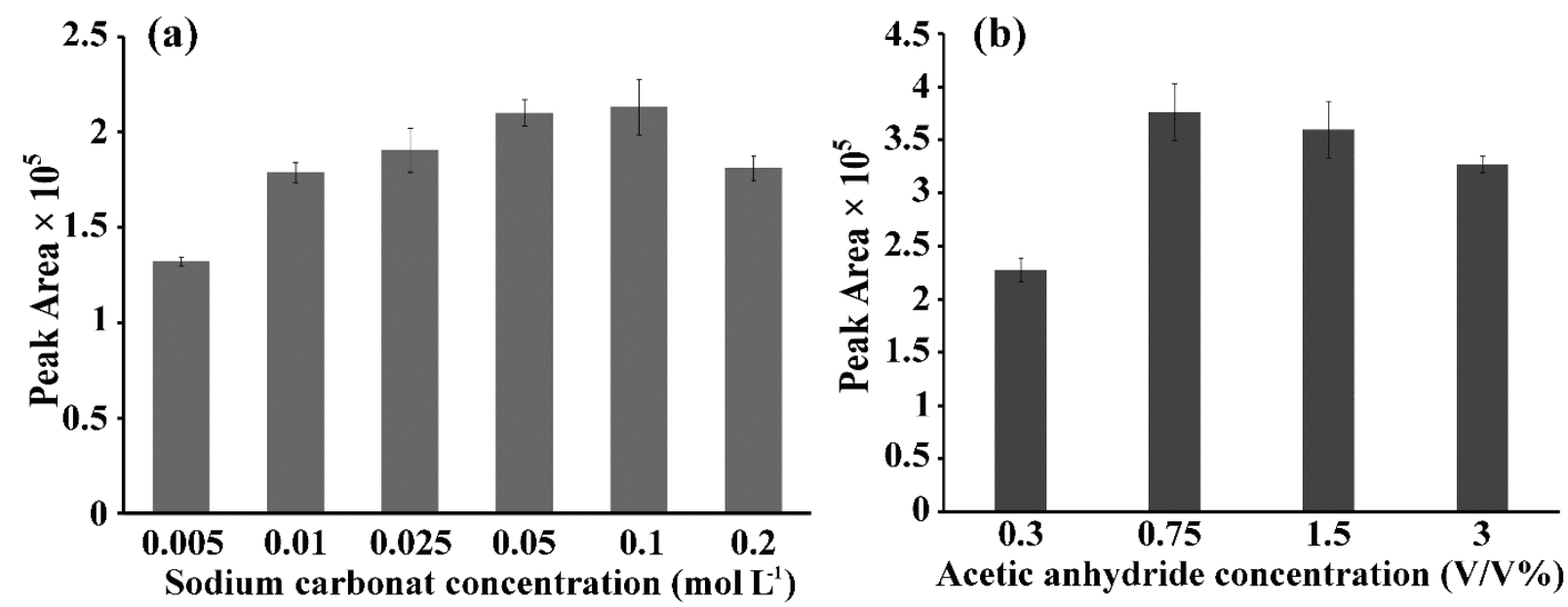

Fig. 3. (a) Effect of sodium carbonate concentration and (b) effect of acetic anhydride amount on the derivatization efficiency of bisphenol A (sample volume, $3 \mathrm{~mL}$; concentration of analyte, $200 \mu \mathrm{g} \mathrm{L}^{-1}$; amount of acetic anhydride (for (a)), $10 \mu \mathrm{L}$; amount of sodium carbonat (for (b)), $0.05 \mathrm{~mol} \mathrm{~L}^{-1}$; reaction time, 5 min; salt addition, $0.1 \mathrm{~g} \mathrm{~mL}^{-1}$; stirring rate, $400 \mathrm{rpm}$; extraction time, $30 \mathrm{~min}$ ). 

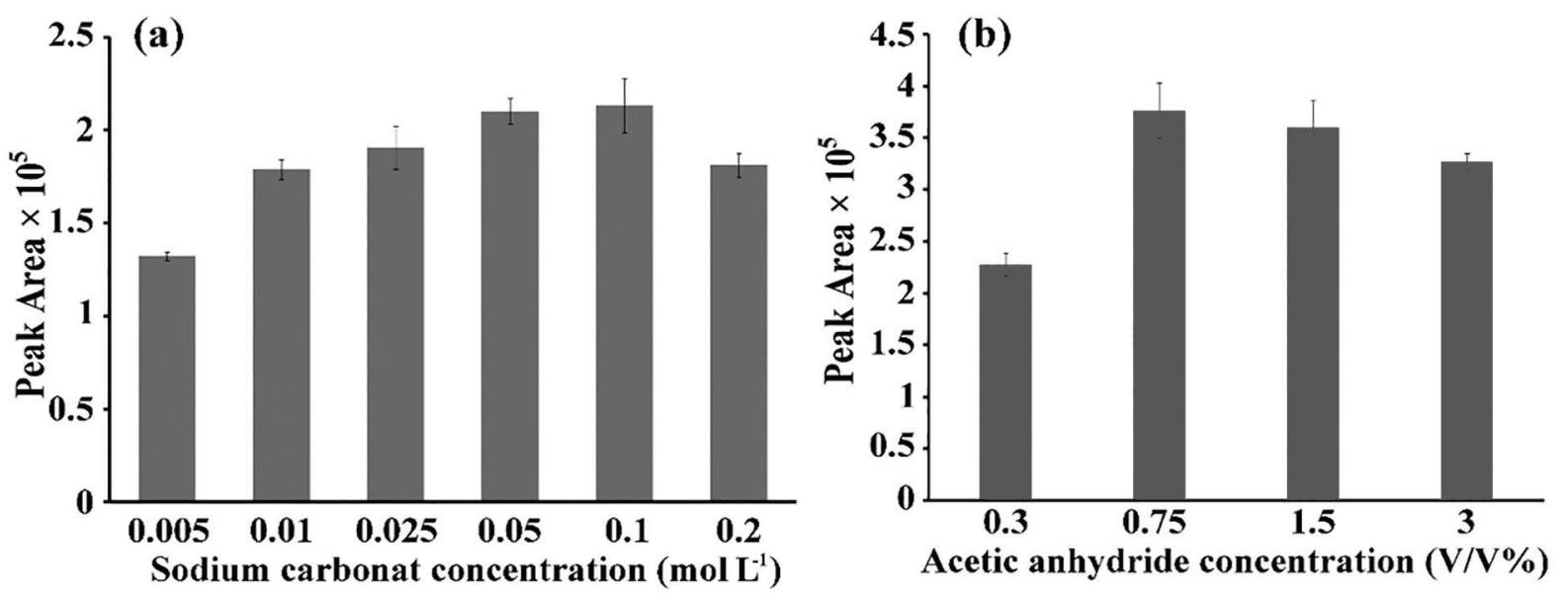

Fig. 4. (a) Effect of salt addition and (b) stirring rate on extraction of bisphenol A (sample volume, $3 \mathrm{~mL}$; analyte concentration, $200 \mu \mathrm{g} \mathrm{L}^{-1}$; $0.05 \mathrm{~mol} \mathrm{~L}^{-1}$ sodium carbonate; amount of acetic anhydride, $25 \mu \mathrm{L}$; reaction time, 5 min; stirring rate (for (a)), $400 \mathrm{rpm}$; salt addition (for (b)), $0.3 \mathrm{~g} \mathrm{~mL}^{-1}$; extraction time, $30 \mathrm{~min}$ at room temperature).
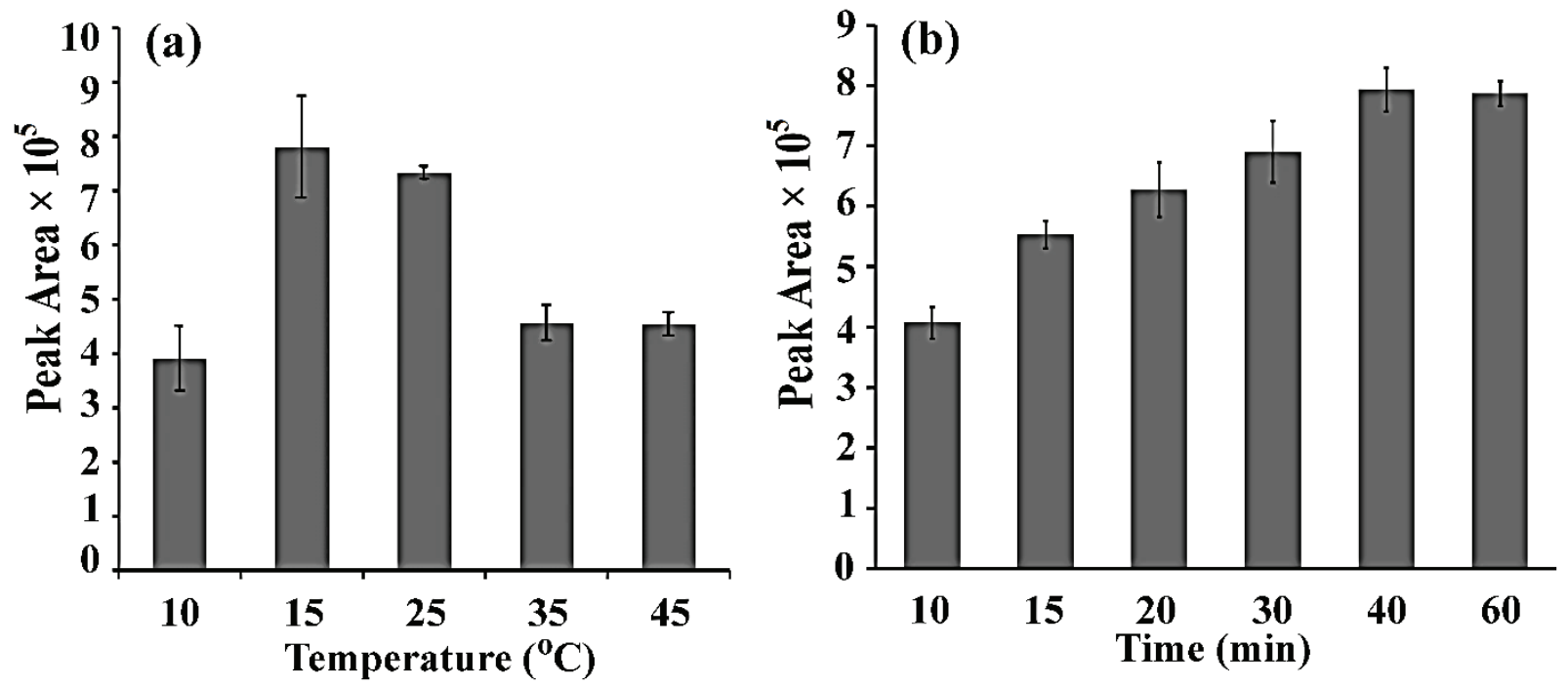

Fig. 5. (a) Effect of temperature and time on extraction of bisphenol A (sample volume, $3 \mathrm{~mL}$; analyte concentration, $200 \mu \mathrm{g} \mathrm{L}^{-1} ; 0.05 \mathrm{~mol} \mathrm{~L}^{-1}$ sodium carbonate; amount of acetic anhydride, $25 \mu \mathrm{L}$; reaction time, $5 \mathrm{~min}$; stirring rate, $600 \mathrm{rpm}$; salt addition, $0.3 \mathrm{~g} \mathrm{~mL}^{-1}$; extraction time (for a), $30 \mathrm{~min}$ at room temperature (for b).

\subsection{Method validation}

The linearity, the repeatability and the detection limits of the proposed method were investigated. The correlation coefficient $(0.9981)$ indicated a good linearity between $2-500 \mu \mathrm{g} \mathrm{L}^{-1}$. Under optimal conditions, LOD was achieved $0.6 \mu \mathrm{g} \mathrm{L}^{-1}$. Relative standard deviation for intra- and inter day were 4.0 and $6.1 \%$, respectively. The amount of $6.8 \%$ was attained for fiber-to-fiber relative standard deviation too. On the other hands, extraction capability of the POAP coated fiber was compared with commercial
SPME fibers. Poly acrylate (PA) and poly dimethylsiloxane/divinylbenzen

(PDMS/DVB) commercial fiber were chosen for this comparison. Figure 6 shows the results. POAP coated fiber revealed better capacity for extraction of bisphenol A. It seems the chemical composition and surface configurations of coating are two effective factors for this investigation. POAP has more chemical functional groups compared to PA and PDMS/DVB coating. On the other side, POAP nanostructure morphology can help for more and fast extraction. 


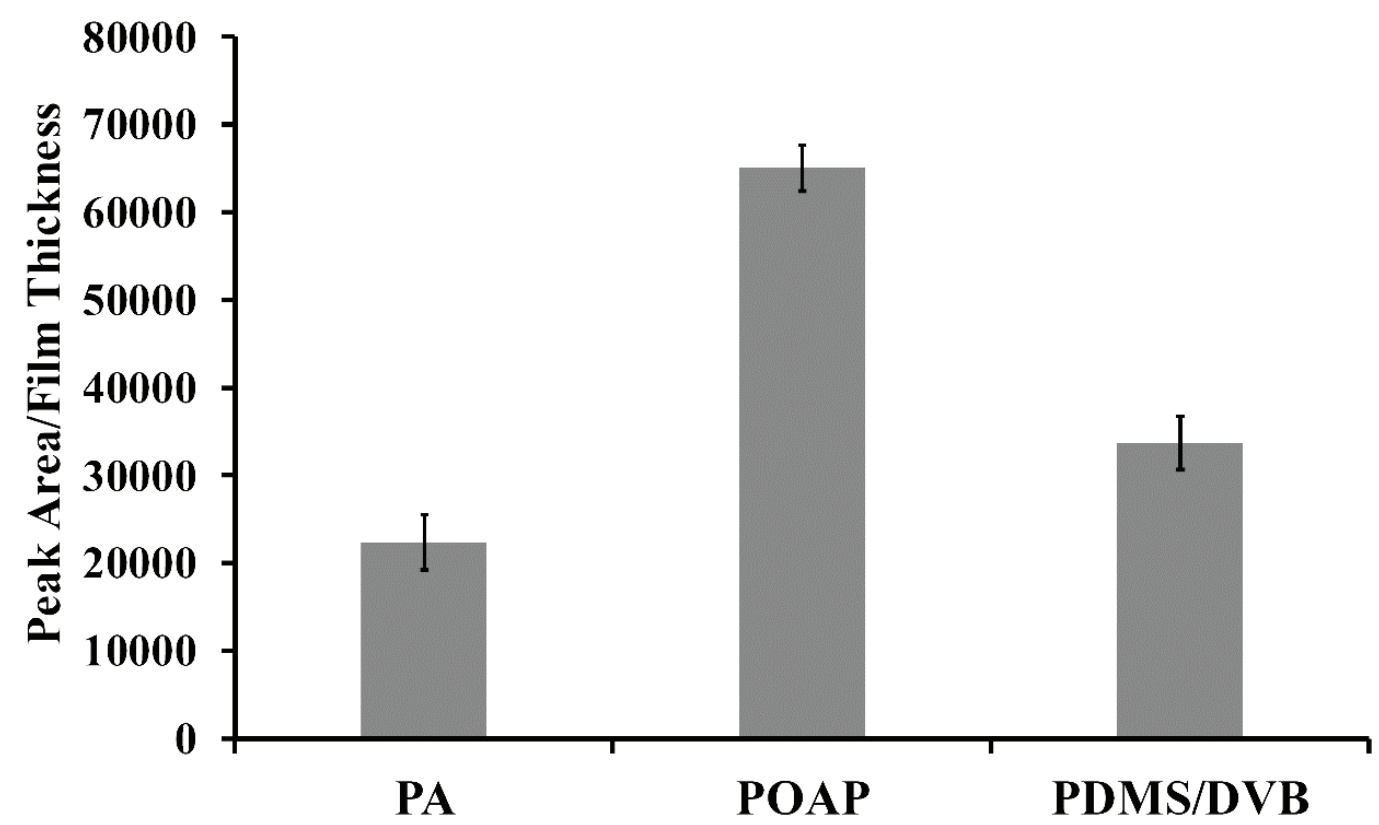

Fig. 6. Comparison of POAP coated SPME fiber with PA \& PDMS/DVB commercial fiber (sample volume, $3 \mathrm{~mL}$; analyte concentration, $50 \mu \mathrm{g} \mathrm{L}^{-1}$; $0.05 \mathrm{~mol} \mathrm{~L}{ }^{-1}$ sodium carbonate; amount of acetic anhydride, $25 \mu \mathrm{L}$; reaction time, $5 \mathrm{~min}$; stirring rate, $600 \mathrm{rpm}$; salt addition, $0.3 \mathrm{~g} / \mathrm{mL}$; extraction time, $30 \mathrm{~min}$ at room temperature).

\subsection{Real sample analysis}

To examine the feasibility of the method, new SPME fiber was applied for analysis of bisphenol A released from milk and drinking water bottle. All the leachate samples were collected from the containers that had been filled with $50 \mathrm{~mL}$ of boiling hot water. Bisphenol A was below the LOD for drinking water bottle but was detected in the range 5-15 $\mu \mathrm{g}$ $\mathrm{L}^{-1}$ in leaching from plastic baby bottle. Relative recovery was attained $98 \pm 3 \%$ for leaching from drinking bottle. Relative recoveries were reported in Table 1. Figure 7 shows the chromatograms from the leaching of baby bottle with and without spiking of bisphenol A. Releasing of bisphenol A from plastic baby bottle was investigated in four time reusing and the results were summarized in Figure 8. As can be seen, bisphenol A exists in the consecutive leaching but the amount of it reduces.

Table 1. Relative recoveries of bisphenol A in different real samples ( $\left.\mu \mathrm{g} \mathrm{L}^{-1}\right)$

\begin{tabular}{lllll}
\hline Added & \multicolumn{2}{l}{ Drinking water bottle } & \multicolumn{2}{l}{ Plastic baby bottle (1 $\mathbf{1}^{\text {st }}$ leachate) } \\
\cline { 2 - 5 } & Found & $\begin{array}{l}\text { Relative } \\
\text { Recovery (\%) }\end{array}$ & Found & $\begin{array}{l}\text { Relative } \\
\text { Recovery (\%) }\end{array}$ \\
\hline 0.0 & ND $^{*}$ & - & 15.1 & - \\
10.0 & 9.7 & 97 & 25.4 & 103 \\
20.0 & 20.6 & 103 & 35.3 & 101 \\
50.0 & 51.0 & 102 & 64.1 & 98 \\
100.0 & 94.1 & 94 & 109.1 & 94 \\
\hline
\end{tabular}

* Not detected. 


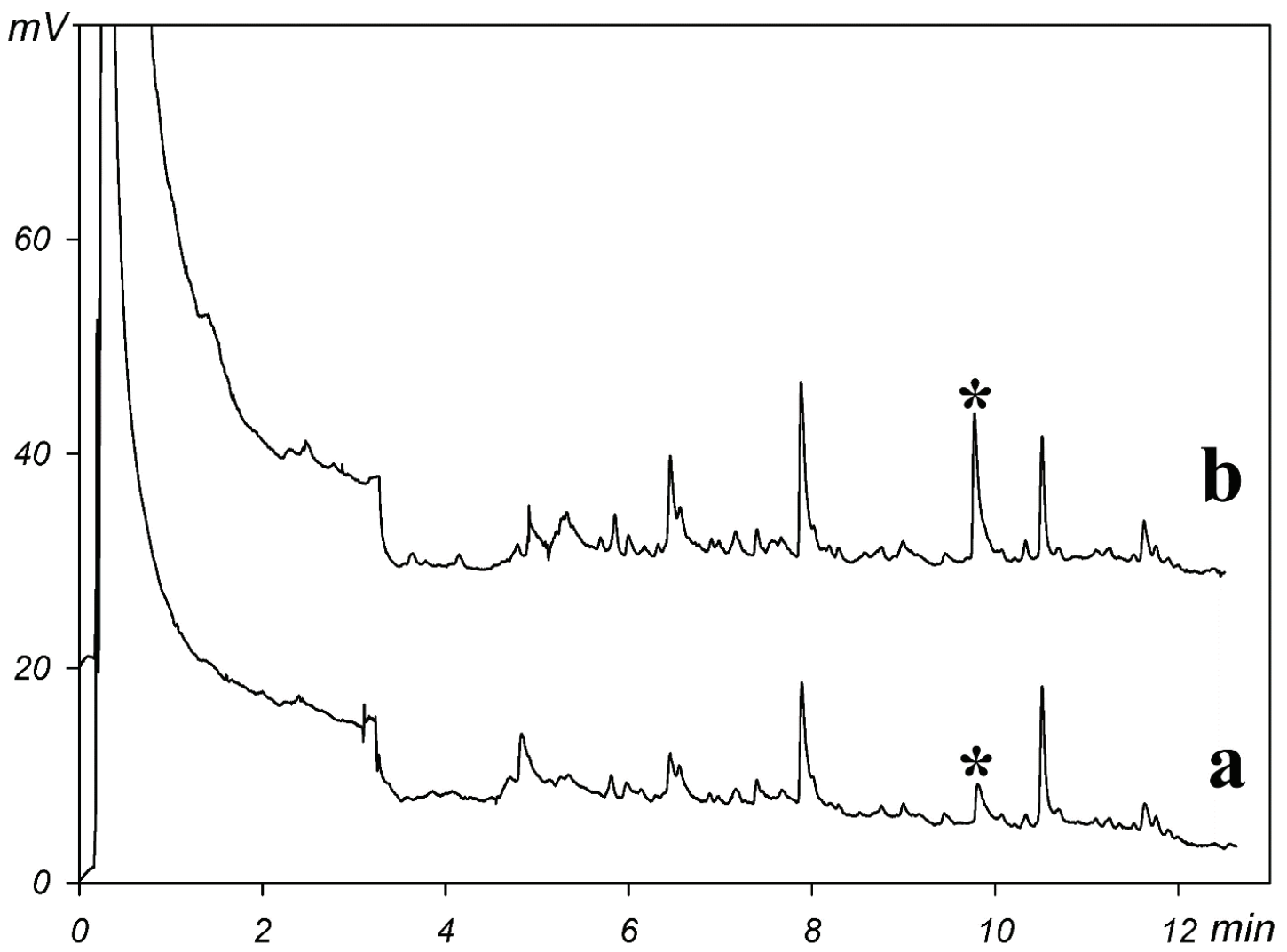

Fig. 7. GC-FID chromatograms after SPME of non-spiked (a) and spiked (b) leaching from plastic baby bottle with $10 \mu \mathrm{g} \mathrm{L}^{-1}$ of bisphenol A.

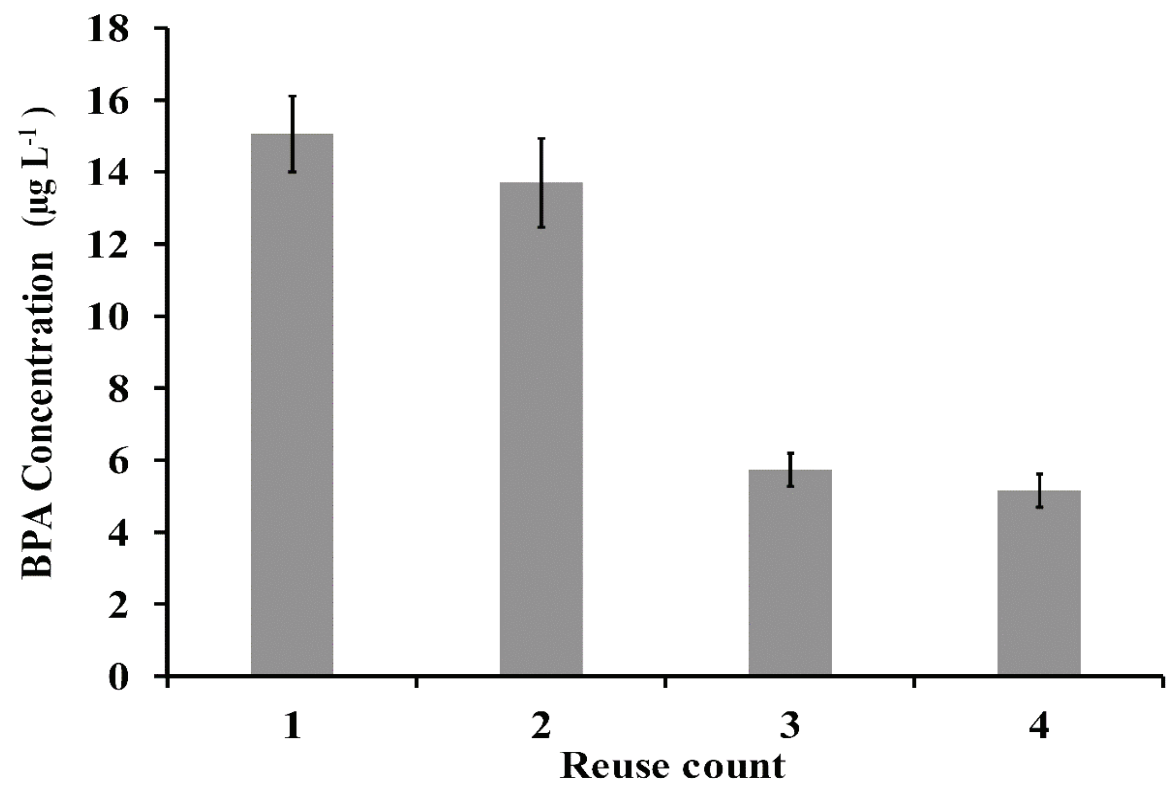

Fig. 8. Determined concentration of bisphenol A (BPH-A) in leaching from plastic baby bottle after four time reusing. 


\section{Conclusions}

This study shows application of nanostructural poly (o-aminophenol) as a new SPME fiber combined with GC-FID is a precise method for reproducibly analyzing trace bisphenol A from aqueous samples. Better chromatographic shape and sensitivity were obtained by derivatization of bisphenol A using acetic anhydride. Different effective parameters were studied and optimized. The figures of merit belonged to the method were favorable. The dynamic range was achieved in the ranges of 2 $500 \mu \mathrm{g} \mathrm{L}^{-1}$. The limits of detection and RSD were $0.6 \mu \mathrm{g} \mathrm{L}^{-1}$ and $<6.8 \%$ respectively. The feasibility of using the SPME-GC-FID system to measure the amount of bisphenol A in leaching from plastic baby and drinking water bottle was tested. Bisphenol A was detected in the range $5-15 \mu \mathrm{g} \mathrm{L}^{-1}$.

\section{Acknowledgment}

The authors are grateful to the Research Council of Isfahan University of Technology (IUT) and the Center of Excellence for Sensor and Green Chemistry for their support of this project.

\section{References}

[1] A. Spietelun, Ł. Marcinkowski, M. De, J. Namie, Recent developments and future trends in solid phase microextraction techniques towards green analytical chemistry, J. Chromatogr. A, 1321 (2013) 1-13.

[2] M. Lashgari, Y. Yamini, An overview of the most common lab-made coating materials in solid phase microextraction, Talanta, 191 (2019) 283-306.

[3] A. Mollahosseini, E. Noroozian, Polyphosphate-doped polypyrrole coated on steel fiber for the solid-phase microextraction of organochlorine pesticides in water, Anal. Chim. Acta, 638 (2009) 169-174.

[4] W. Du, F. Zhao, B. Zeng, Novel multiwalled carbon nanotubes - polyaniline composite film coated platinum wire for headspace solid-phase microextraction and gas chromatographic determination of phenolic compounds, J. Chromatogr. A, 1216 (2009)
3751-3757.

[5] H. Bagheri, A. Roostaie, Aniline - silica nanocomposite as a novel solid phase microextraction fiber coating, J. Chromatogr. A, 1238 (2012) 22-29.

[6] R. Tucceri, Poly (o-aminophenol) film electrodes, Springer International Publishing Switzerland, 2013.

[7] R. Tucceri, P. Arnal, A. Scian, Electrosynthesis and spectroscopic characterization of poly (o-aminophenol) film electrodes, ISRN Polym. Sci., 2012 (2012) 1-26.

[8] C. Barbero, J.J. Silber, L. Sereno, Formation of a novel electroactive film by electropolymerization of ortho-aminophenol, Study of its chemical structure and formation mechanism, Electropolymerization of analogous compounds, J. Electroanal. Chem., 263 (1989) 333-352.

[9] X. Chen, J. Chen, C. Deng, C. Xiao, Y. Yang, Z. Nie, et al., Amperometric glucose biosensor based on boron-doped carbon nanotubes modified electrode, Talanta, 76 (2008) $763-$ 767.

[10] D. Pan, J. Chen, S. Yao, W. Tao, L. Nie, An amperometric glucose biosensor based on glucose oxidase immobilized in electropolymerized poly (o-aminophenol) and carbon nanotubes composite film on a gold electrode, Anal. Sci., 21 (2005) 367-371.

[11] M.A.V. Garcia, P.T. Blancoa, A. Ivaska, A poly (o-aminophenol ) modified electrode as an amperometric hydrogen peroxide biosensor, Electrochim. Acta, 43 (1998) 3533-3539.

[12] N. Kumar, R. N. Goyal, Simultaneous determination of melatonin and 5-hydroxytrptophan at the disposable poly(melamine)/poly-(o-aminophenol) composite modified screen printed sensor, J. Electroanal. Chem., 874 (2020) 114458.

[13] M.C. Miras, A. Badano, M.M. Bruno, C. Barbero, Nitric oxide electrochemical sensors based on hybrid films of conducting polymers and metal phtalocyanines, Port. Electrochim. Acta, 21 (2003) 235-243. 
[14] L. Liu, H. Cui, H. An, J. Zhai, Y. Pan, Electrochemical detection of aqueous nitrite based on poly(aniline-co-o-aminophenol)modified glassy carbon electrode, Ionics, 23 (2017) 1517-1523.

[15] A. B. Slimane, A. F. Al-Hossainy, M. S. Zoromba, Synthesis and optoelectronic properties of conductive nanostructured poly(aniline-co-o-aminophenol) thin film, J. Mater. Sci.: Mater. Electron., 29 (2018) 84318445.

[16] S. Mu, Catechol sensor using poly (anilineco- o-aminophenol) as an electron transfer mediator, Biosens. Bioelectron., 21 (2006) 1237-1243.

[17] L. Zhang, J. Lian, Electrochemical synthesis of copolymer of aniline and o-aminophenol and its use to the electrocatalytic oxidation of ascorbic acid, J. Electroanal. Chem., 611 (2007) 51-59.

[18] W. Zhaoyang, Z. Xiaolei, Y. Yunhui, S. Guoli, Y. Ruqin, A sensitive nicotine sensor based on molecularly imprinted electropolymer of o-aminophenol, Front. Chem. China, 32 (2006) 183-187.

[19] A. Ballesteros-gómez, S. Rubio, D. Pérezbendito, Analytical methods for the determination of bisphenol A in food, J. Chromatogr. A, 1216 (2009) 449-469.

[20] R.T. Zoeller, R. Bansal, C. Parris, Bisphenol-A , an environmental contaminant that acts as a thyroid hormone receptor antagonist in vitro, increases serum thyroxine, and alters RC3 / neurogranin expression in the developing rat brain, Endocrinology, 146 (2004) 607-612.

[21] Y.B. Wetherill, C.E. Petre, K.R. Monk, A. Puga, K.E. Knudsen, The xenoestrogen bisphenol A induces inappropriate androgen receptor activation and mitogenesis in prostatic adenocarcinoma cells 1 , Mol. Cancer Ther., 13 (2002) 515-524.

[22] B.T. Akingbemi, C.M. Sottas, A.I. Koulova, G.R. Klinefelter, M.P. Hardy, Inhibition of testicular steroidogenesis by the xenoestrogen bisphenol A is associated with reduced pituitary luteinizing hormone secretion and decreased steroidogenic enzyme gene expression in rat leydig cells, Endocrinology, 145 (2004) 592-603.

[23] P. Viñas, N. Campillo, Comparison of two derivatization-based methods for solid-phase microextraction - gas chromatography - mass spectrometric determination of bisphenol A, bisphenol S and biphenol migrated from food cans, Anal. Bioanal. Chem., 397 (2010) 115125.

[24] M.K.R. Mudiam, R. Jain, V.K. Dua, A.K. Singh, V.P. Sharma, Application of ethyl chloroformate derivatization for solid-phase microextraction- gas chromatography-mass spectrometric determination of bisphenol-A in water and milk samples, Anal. Bioanal. Chem., 401 (2011) 1695-1701.

[25] W. Gao, J. Cheng, X. Yuan, Y. Tian, Covalent organic framework-graphene oxide composite: A superior adsorption material for solid phase microextraction of bisphenol A, Talanta, 222 (2021) 121501.

[26] Y. H. Pang, Y.Y. Huang, X. F. Shen, Y. Y. Wang, Electro-enhanced solid-phase microextraction with covalent organic framework modified stainless steel fiber for efficient adsorption of bisphenol A, Anal. Chim. Acta, 1142 (2021) 99-107.

[27] N. Mohammadnezhad, A. A. Matin, N. Samadi, A. Shomali, H. Valizadeh, Ionic liquid-bonded fused silica as a new solidphase microextraction fiber for the liquid chromatographic determination of bisphenol A as an endocrine disruptor, J. AOAC Int., 100 (2017) 218-223.

[28] Y. Liu, Y. Liu, Z. Liu, F. Du, G. Qin, G. Li, X. Hu, Z. Xu, Z. Cai, Supramolecularly imprinted polymeric solid phasemicroextraction coatings for synergetic recognition nitrophenols and bisphenol A, J. Hazard. Mater., 368 (2019) 358-364

[29] S. Kunimura, T. Ohsaka, N. Oyama, Preparation of thin polymeric films on electrode surfaces by electropolymerization of 
o-aminophenol, Macromolecules, 21 (1988) 894-900.

[30] J.M. Ortega, Conducting potential range for poly (o-aminophenol), Thin Solid Films, 371 (2000) 28-35.

[31] D. Gonc, R.C. Faria, M. Yonashiro, L.O.S. Bulhoes, Electrochemical oxidation of o-aminophenol in aqueous acidic medium: formation of film and soluble products, J. Electroanal. Chem., 487 (2000) 90-99.

[32] A.A. Shah, R. Holze, Poly (o-aminophenol) with two redox processes: A spectroelectrochemical study, J. Electroanal. Chem., 597 (2006) 95-102.

[33] A.Q. Zhang, C.Q. Cui, Y.Z. Chen, J.Y. Lee, Synthesis and electrochromic properties of poly-o-aminophenol, J. Electroanal. Chem., 373 (1994) 115-121.

[34] A.Q. Zhang, C.Q. Cui, J.Y. Lee, Metalpolymer interactions in the $\mathrm{Ag}+$-poly-oaminophenol system, J. Electroanal. Chem., 413 (1996) 143-151.

[35] A. Guenbour, A. Kacemi, A. Benbachir, L. Aries, Electropolymerization of 2-aminophenol Electrochemical and spectroscopic studies, Prog. Org. Coat., 38 (2000) 121-126.

[36] S.M. Sayyah, M.M. El-Rabiey, S.S.A. Elrehim, R.E. Azooz, Electropolymerization kinetics of o-aminophenol and characterization of the obtained polymer films, J. Appl. Polym. Sci., 99 (2006) 3093-3109.

[37] R. Ojani, J. Raoof, S. Fathi, Poly (o-aminophenol) film prepared in the presence of sodium dodecyl sulfate: Application for nickel ion dispersion and the electrocatalytic oxidation of methanol and ethylene glycol, Electrochim. Acta, 54 (2009) 2190-2196.

[38] A. Mohammadi, Y. Yamini, N. Alizadeh, Dodecylsulfate-doped polypyrrole film prepared by electrochemical fiber coating technique for headspace solid-phase microextraction of polycyclic aromatic hydrocarbons, J. Chromatogr. A, 1063 (2005) $1-8$.
[39] N. De Coensel, F. David, P. Sandra, Study on the migration of bisphenol-A from baby bottles by stir bar sorptive extraction- thermal desorption-capillary GC-MS, J. Sep. Sci., 32 (2009) 3829-3836.

[40] N. Rastkari, R. Ahmadkhaniha, M. Yunesian, L.J. Baleh, A. Mesdaghinia, Sensitive determination of bisphenol $\mathrm{A}$ and bisphenol $F$ in canned food using a solid-phase microextraction fibre coated with singlewalled carbon nanotubes before GC/MS, Food Addit. Contam., 27 (2010) 1460-1468. 